\title{
PLANEJAMENTO, ORDENAMENTO E GESTÃO INTEGRADA \\ REGULARIZAÇÃO FUNDIÁRIA E POLÍTICAS DE REGULAÇÃO URBANO-AMBIENTAL: O CASO DO DISTRITO FEDERAL/BRASIL.
}

\author{
Gisele Victor Batista (AUTOR PRINCIPAL) - giselevictorbatista @ gmail.com \\ Harpia Meio Ambiente EIRELI ME \\ Nadine Victor Batista (COAUTOR) - nadinebatista@gmail.com \\ Instituto Universitário de Lisboa - ISCTE:IUL - Doutoranda em Políticas Públicas
}

\begin{abstract}
Resumo: A urbanização de Brasília está vinculada a políticas de ocupação do interior brasileiro, a qual foi concretizada pelo governo de Juscelino Kubitschek, na década de 1950. O processo de ocupação deu-se de maneira acelerada, embora tardia, decorrendo em ocupação irregular, com registro de mais de 300 condomínios irregulares, muitos deles considerados como área de interesse social, no que tange ao processo de regularização fundiária. Neste contexto, este trabalho apresentou análise do processo de regularização fundiária, sob a perspectiva urbano-ambiental e de políticas públicas, com ênfase na Lei Federal $\mathrm{N}^{\mathrm{o}} 12.657 / 2012$, Lei Federal $\mathrm{N}^{\mathrm{o}} 11.977 / 2009$ e Lei Federal $\mathrm{N}^{\mathrm{o}} 12.527 / 2011$. Os resultados obtidos demonstraram que tanto o Novo Código Florestal, quanto o Programa Minha Casa, Minha Vida, permitem a ocupação das áreas de preservação permanente, dando ênfase ao componente social, sem negligenciar a qualidade do meio ambiente. Ainda, constatou-se que o Governo Distrital busca disponibilizar informações a respeito da regularização fundiária, promovendo conhecimento à sociedade e alertando a mesma sobre possíveis penalidades em casos de grilagem na capital federal. Nos sites oficiais visualiza-se o status do processo de regularização e agência de fiscalização informa as áreas sujeitas à infração, caso ocupadas de maneira ilegal e irregular. Contudo, apesar de as informações serem prestadas de maneira clara e os sites possuem acesso fácil, sem demora nos carregamento dos mapas disponíveis, existe pouca interatividade em termos de comunicação com o cidadão, e por consequência, caracteriza-se como baixa promoção de cidadania em termos de conscientização ambiental.
\end{abstract}

Palavras-chave: Regularização Fundiária, Área de Regularização de Interesse Específico, Área de Preservação Permanente e Governo Eletrônico.

\section{INTRODUÇÃO E OBJETIVOS}

Este trabalho tem como objetivo apresentar uma análise referente ao processo de regularização fundiária no Distrito Federal, sob a perspectiva ambiental e de políticas públicas, com ênfase na Lei Federal No12.657/2012 (Novo Código Florestal), Lei Federal No11.977/2009 (Programa Minha Casa, Minha Vida) e Lei Federal No 12.527/2011(Lei de Acesso à Informação). A questão central do artigo é a possibilidade de legalização de ambientes altamente antropizados, pois o Novo Código Florestal e o Programa Minha Casa Minha Vida permitem a ocupação das áreas de preservação permanente, em casos de 

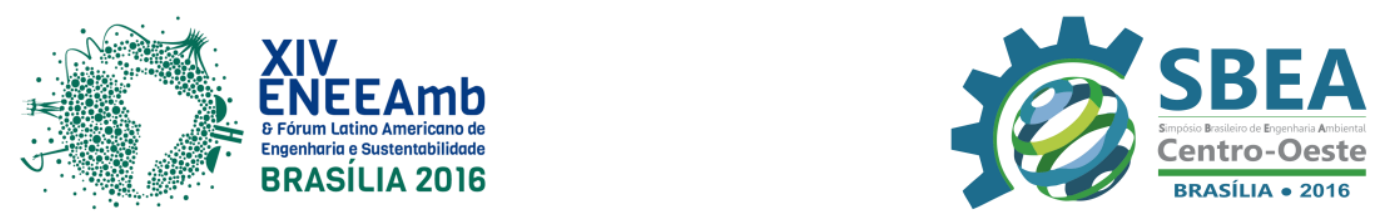

regularização fundiária de interesse específico, bem como é direito do cidadão, enquanto construtor coletivo do conhecimento, ter acesso às informações das áreas passiveis de urbanização.

Para tanto, este trabalho recorreu ao território do Distrito Federal como universo de estudo, tendo em vista as peculiaridades locais que tornam as análises mais enriquecedoras: a capital federal possui uma ocupação recente; teve um acelerado processo de urbanização, impulsionado pela migração de brasileiros de diversas regiões, bem como abriga inúmeros estrangeiros; a forma de acesso à terra possui uma lógica diferenciada das demais cidades; é uma região metropolitana, exercendo função de centralidade urbana para 23 municípios, em dois Estados vizinhos - Minas Gerais e Goiás; e tem um ambiente natural formado por áreas de sensibilidade ambiental, devido à grande quantidade de mananciais, áreas de preservação e outras áreas, que restringem o uso do solo, urbano e rural. Para que estes problemas fossem revertidos, o Governo do Distrito Federal implantou políticas públicas de regularização territorial, com vistas à melhoria da qualidade ambiental, além de informar aos cidadãos as áreas propícias à ocupação, como mecanismo de prevenção à prática de grilagem.

A implantação de um sistema de transparência governamental, como $e$-gov, que informe áreas sujeitas à urbanização tem ganhado, cada vez mais, espaço nas políticas de regulação urbano-ambiental do Distrito Federal. Conforme Jardim (2005), a política do e-gov viabiliza possibilidades de cooperação entre os próprios organismos do governo, de modo a melhorar a fiscalização de áreas irregulares e realizar transações efetivadas mais rapidamente, menos burocráticos, com menor grau de fragmentação e redundância de informações.

Desta forma, segundo Ribeiro et al (2011), o e-gov gera conhecimento, tanto dentro das instituições do governo, quando os organismos governamentais possuem a devida interação para que possam se comunicar sobre as irregularidades ambientais e promover as devidas exigências, quanto ao cidadão que pode acompanhar via portal do governo e suas agências reguladoras as informações sobre o território. Neste contexto, para Brasil (2000), o governo eletrônico ganha relevância em duas relações com o governo: G2G (do inglês governmento to government), tratando-se da relação governo entre governo, estabelecida tanto de forma vertical entre instituições das três esferas de governo, quanto horizontal, relacionando-se com os órgãos de mesmo nível governamental); e, $\mathrm{G} 2 \mathrm{C} 2 \mathrm{C}$ (do inglês government to citizen to government), ou seja, a relação entre governo e cidadão numa via dupla de comunicação, isto é, ao mesmo tempo que o governo mantém suas informações abertas para que o cidadão possa acessá-las virtualmente; ele disponibiliza mecanismos de comunicação que permita este questionar sobre as ações e projetos realizados e obter os dados necessários a regularização das áreas ambientais.

Nestes termos, e levando-se em consideração a ocupação ordenada do território, a comunicação clara e eficaz entre os entes do governo, e entre eles e o cidadão, é de suma importância para celeridade do processo de regularização fundiária. $\mathrm{O}$ e-gov pode constituirse numa importante ferramenta de regulação urbano-ambiental, que deve ser usada para difundir informações relevantes à comunidade, bem como melhorar o atendimento de suas necessidades, sobretudo as ocupações em áreas de preservação permanente (APPs), tão comuns no Distrito Federal.

As APPs foram definidas pelo Novo Código Florestal como mecanismos de proteção e conservação dos recursos naturais, o que significa que não são apropriadas à ocupação humana e devem estar cobertas com a vegetação original. A presença da vegetação nativa é para atenuar os efeitos erosivos e a lixiviação dos solos, contribuindo, também, para 

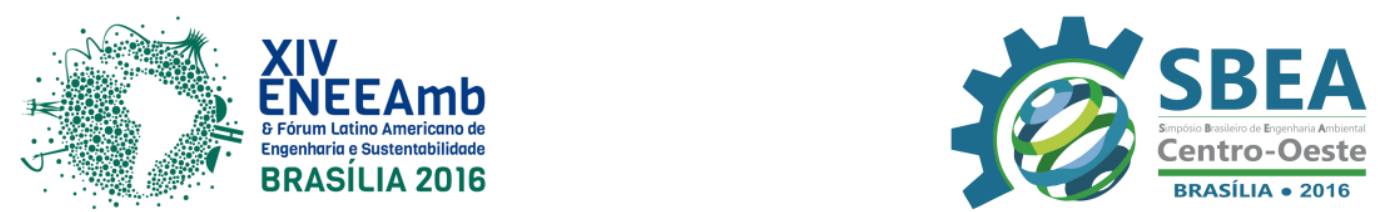

regularização do fluxo hídrico, redução do assoreamento dos cursos d'água e reservatórios e trazendo, também, benefícios à fauna.

Cabe destacar que o Código Florestal, informa que as APPs devem ser consideradas como faixa de preservação, mesmo nos casos em que a cobertura vegetal não estiver presente, a qual deve ser recuperada com a arborização de espécies nativas, de acordo com a Resolução CONAMA nº 429/2011. Até 2009, a intervenção em APPs só era permitida em casos excepcionais, de utilidade pública, de interesse social ou baixo impacto ambiental, como dispunha a Resolução CONAMA no 369/2006.

Contudo, com a implantação da Lei Federal No 11.977 de 2009 e Lei Federal № 12.651 de 2012 e suas alterações, ocorreu uma flexibilização legal para ocupação humana em APPs, mas impondo alguns requisitos. Neste contexto, o Art. 54 da Lei Federal $\mathrm{N}^{\circ} 11.977 / 2009$, informa que o projeto de regularização fundiária de interesse social deverá considerar as características da ocupação e da área para definir parâmetros urbanísticos e ambientais específicos, além de identificar os lotes, as vias de circulação e as áreas destinadas a uso público. Ainda, a regularização fundiária de interesse social em APP será admitida pelos Estados quando o município não for competente para o licenciamento ambiental.

No que tange ao Novo Código Florestal (Lei Federal No 12.651/2012), Seção II o Regime de Proteção das Áreas de Preservação Permanente, o Art. $8^{\circ}$ trata de intervenção ou a supressão de vegetação nativa em APP, estas somente ocorrerão nas hipóteses de utilidade pública, de interesse social ou de baixo impacto ambiental previstas nesta Lei. Disciplina, também, a utilização dos espaços das APPs, nos casos de regularização fundiária de interesse social, de assentamentos inseridos em área urbana de ocupação consolidada e que ocupam APP não identificadas como áreas de risco, dispondo que a regularização ambiental será admitida por meio da aprovação do projeto de regularização fundiária, na forma da Lei no $11.977 / 2009$.

Para tanto, nos projetos de regularização fundiária, deve ocorrer a indicação das faixas ou áreas em que devem ser resguardadas as características típicas da APP, com a devida proposta de recuperação de áreas degradadas, e daquelas não passíveis de regularização, salientando os riscos ambientais. Ao longo dos rios ou de qualquer curso d'água, deverá ser mantida faixa não edificável com largura mínima de 15 (quinze) metros de cada lado, podendo ser redefinida quando em áreas urbanas tombadas como patrimônio histórico e cultural.

Neste tipo de projeto, considera-se que maior ênfase deve ser dada à comprovação da melhoria das condições de sustentabilidade urbano-ambiental, a partir do projeto de regularização. Isto se deve, também, à participação popular nas decisões sobre a composição do território e parâmetros para urbanização, onde o componente social ganhou maior representatividade, com poder regulativo. A este respeito, cita-se a Lei Federal $\mathrm{N}^{\circ}$ 12.527/2011, a qual trata que os sites governamentais devem fornecer serviços de utilidade pública, bem como disponibilidade de informação que auxilie o cidadão no seu cotidiano, trazendo maior eficiência na gestão pública.

No Distrito Federal, a consolidação das informações provenientes de distintas secretarias de governo busca alertar a população sobre as áreas disponíveis à urbanização, as quais seguem as leis urbano-ambientais. Contudo, a formação socioespacial da capital federal, com expressivo histórico de ocupação irregular, aliada à carência de ofertas de habitação a preços acessíveis à maior parcela da população, tem impulsionado, sobremaneira, a demanda por assentamentos ilegais.

Atualmente, o desafio do governo distrital consiste conciliar o processo de regularização fundiária aos dispositivos legais, que permitam a ocupação em APPs de 

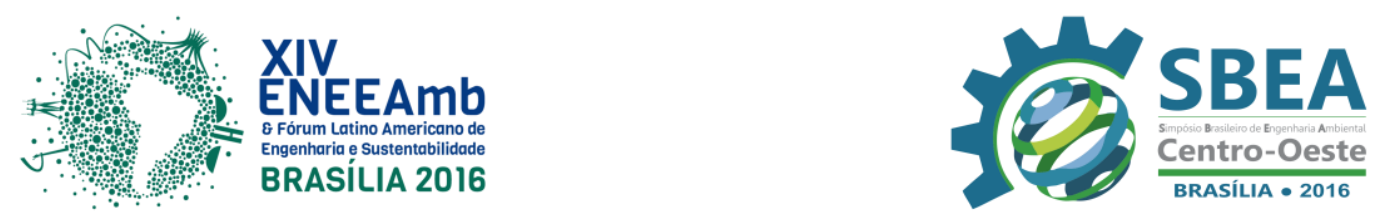

maneira sustentável, mas, também, conter o avanço de novas áreas irregulares, no intuito de preservar o meio ambiente e permitir a ordenação urbana. Para tanto, pode contar com as ferramentas do governo eletrônico, criando uma comunicação transparente, desburocratiza e eficiente.

\section{METODOLOGIA}

\subsection{Pesquisa documental e levantamento de dados}

Para o melhor conhecimento da área do estudo foi necessário realizar uma pesquisa e levantamento do todo o material disponível sobre a região de Brasília. Foram investigadas produções científicas elaboradas por universidades e órgãos institucionais (Instituto Brasileiro de Geografia e Estatística - IBGE, Instituto de Pesquisa Econômica Aplicada - IPEA, Secretaria de Planejamento Urbano, CODEPLAN - Companhia do Desenvolvimento do Planalto Central, Estatística e Administrações Regionais. Foram consultados, ainda, os sítios oficiais das secretarias de Governo do Distrito Federal.

\subsection{Levantamento da legislação pertinente à matéria}

Foram consultadas as legislações federais e distritais sobre o uso do solo e e-gov, utilizando-se sempre como parâmetro a norma legal, conforme determina a constituição federal. O embasamento legal foi de suma importância para a composição deste artigo, pois permitiu um melhor tratamento da questão, levando-se em consideração a qualidade do ambiente natural e a equidade social.

\subsection{Elaboração do texto final}

Após a conclusão das etapas anteriores, foi possível realizar a consolidação e análise dos dados, do qual decorreu a elaboração deste artigo.

\section{RESULTADOS E DISCUSSÕES}

\subsection{Breve histórico do processo de ocupação do Distrito Federal}

A formação socioespacial da cidade de Brasília, na década de 1950, está relacionada a uma política de promoção do povoamento e desenvolvimento da região CentroOeste do país, que até então estava concentrada no eixo Rio-São Paulo. Na época, o projeto aprovado foi estruturado para atender a uma população de 600 mil habitantes, ao final de 2000, mas as fortes correntes migratórias promoveram uma população para perto de 2 milhões de habitantes, em 2000, e para 2.469,489 milhões de habitantes em 2010 (IBGE, 2010).

O fenômeno da migração tem grande representatividade no Distrito Federal, tendo em vista que a cidade foi implantada num local onde não havia nenhum núcleo urbano CODEPLAN (2014). Por volta de 1950, famílias de nordestinos destinaram-se à nova capital do país para servir de mão-de-obra na construção civil. Após a inauguração da cidade, as obras continuaram por muito tempo e em ritmo acelerado, pois havia a necessidade de construção das cidades-satélites, atuais regiões administrativas. Na década de 1970, cidades como Gama, Taguatinga, Candangolândia e Núcleo Bandeirante foram erguidas para abrigar esses trabalhadores que pretendiam fixar-se na capital, bem como atender população de baixa renda que estavam deslocando-se para Brasília. 

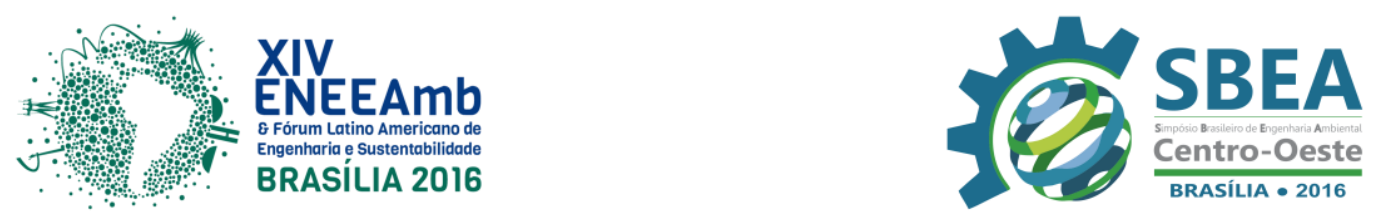

A segunda leva de migrantes, a partir de 1970, correspondia a uma mão de obra mais especializada para atender ao comércio e serviços, bem como para compor o quadro técnico e administrativo do serviço público. Na década de 1980, o acréscimo da população residente no entorno do Plano Piloto era de 1,6\% ao ano e, no início de 1990, esse índice subiu para 3,57\%; ao final desta década o crescimento populacional subiu para cerca de $5 \%$.

Em 2003, o crescimento populacional teve uma expressiva alta, passando para $13,9 \%$ ao ano. O censo do IBGE de 2000 registrou que dos 2.051.146 habitantes, 1.094.303 eram migrantes de outros estados, sendo que desse total, cerca de 400 mil pessoas residiam na cidade a menos de 10 anos. Este fato demonstra que Brasília é uma cidade em construção e que, ainda, é uma região de forte atração populacional.

O histórico da ocupação de Brasília resume-se, basicamente, na vocação desse trecho em consolidar-se, ao longo do tempo, como polo econômico, visando o desenvolvimento da região Centro-Oeste. Contudo, a crescente urbanização teve seu lado negativo, do ponto de vista da regularização da terra, pois inúmeras chácaras que foram inicialmente concedidas à produção agrícola, para abastecer o Plano Piloto, foram sendo parceladas diante da carência de política habitacional.

Atualmente, segundo informações da Agência de Desenvolvimento do Distrito Federal (Terracap, 2016), foi elaborado um estudo, em 2006, que revelou a existência de 513 parcelamentos irregulares, dos quais 379 constituídos em zona urbana e 134 na zona rural. Dos parcelamentos urbanos, 347 eram informais, 28 estavam em processo de regularização e 4 eram regulares, com registro em cartório. Desses situados em área urbana, 189 estavam em terras não desapropriadas ou de particular, 88 estavam em áreas desapropriadas e 40 em terras desapropriadas em comum, pertencentes a particulares e ao governo, mas sem divisão e demarcação. Ainda, informou que 202 parcelamentos urbanos, com 347.434 habitantes, estavam localizados em setores habitacionais criados, correspondendo a $65 \%$ da população que habitava em parcelamentos urbanos informais.

Para a tratativa do problema, a Terracap agrupou os parcelamentos consolidados, quando possível, em Áreas de Regularização e estas em Setores Habitacionais de Regularização, agregando áreas desocupadas para fins de estruturação viária, implantação de equipamentos comunitários públicos e privados, equipamentos urbanos e áreas verdes livres. Estas informações foram compiladas no Plano de Desenvolvimento e Ordenamento Territorial do Distrito Federal, o qual serve como diretriz para políticas de regularização da terra.

\subsection{Plano de Desenvolvimento de Ordenamento Territorial}

Em resposta ao processo acelerado de transformação do uso do solo, vários planos de ordenamento territorial foram criados, desde 1977. Os principais desafios eram efetuar a regularização das terras desapropriadas, ainda da época da criação da cidade, para tornar o acesso à terra num processo legal e desburocratizado.

Nesta linha, o Plano de Desenvolvimento e Ordenamento Territorial - Lei Distrital No803/2009 e suas alterações, instituiu no Artigo 125 as Áreas de Regularização, que são classificadas em Áreas de Regularização de Interesse Social - ARIS e Áreas de Regularização de Interesse Específico - ARINE. Por meio da "Estratégia de Regularização Fundiária" constante do PDOT/09 foram criados 29 Setores Habitacionais de Regularização, dentro dos quais foram definidas 39 Áreas de Regularização de Interesse Específico - ARINE e 22 Áreas de Regularização de Interesse Social - ARIS. Foram criadas, ainda, 6 Áreas de Regularização de Interesse Específico - ARINE e 14 Áreas de Regularização de Interesse Social - ARIS, localizadas fora de Setores Habitacionais de Regularização. Complementando a Estratégia de Regularização Fundiária, 27 parcelamentos localizados em zona rural foram 

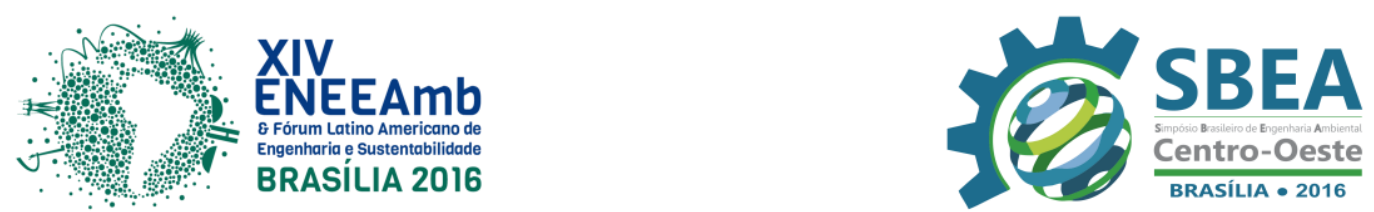

definidos como Parcelamentos Urbanos Isolados - PUI, dos quais 5 foram classificados como de Interesse Específico e 22 como de Interesse Social.

Apesar da prioridade no processo de regularização fundiária, a Lei Orgânica do Distrito Federal dispõe as normas e garantias de proteção ao meio ambiente, conforme artigos 278 a 311, tais como estudo ambiental, licenciamento ambiental, proteção de unidades de conservação, dentre outros. Esses dispositivos corroboram as disposições da Constituição Federal de 1988, ressaltando o entendimento de que há o dever legal de proteção do meio ambiente por parte do Estado e da coletividade.

\subsection{Aplicação do Novo Código Florestal e Minha Casa, Minha Vida em ARINE no DF}

Em 2009, a Terracap licitou o projeto integrado para regularização fundiária da ARINE Arniqueira, composta por três frentes de regularização: Setor Habitacional Arniqueira (1.398,51 hectares), Setor Habitacional Bernardo Sayão (110,63 hectares) e áreas intersticiais do Setor de Mansões Park Way Trecho 3 (939,31 hectares). As diretrizes de ocupação traçadas definiram que as edificações que se encontravam em APP, deveriam ser demolidas e a área objeto de projeto de recuperação e área degradada.

Segundo Batista et al (2013), o Estudo de Impacto Ambienta deliberou que as APPs de cursos d'água teriam como base os Artigos $4^{\circ}$ e 65 do Novo Código Florestal, sendo que este último possibilita uma flexibilização da faixa de preservação de 30 para 15 metros, em áreas urbanas consolidadas não mapeadas como áreas de risco e que estivessem inseridas em ARINE. Com isso, a delimitação da APP na ARINE Arniqueira foi estudada caso a caso, para que se alcance a ajustiça social e a qualidade ambiental.

Em função da ocupação local não respeitar um padrão de urbanização, os cursos d'água que se enquadraram no Artigo 65, foram tratados caso a caso, para reduzir o impacto socioambiental. Para isso, as linhas de APPs de curso d'água em local com ocupação consolidada foi de, no mínimo de 15 metros, tendo como referência a rede hidrográfica gerada no estudo ambiental. Porém, nas áreas em que não havia a consolidação urbana, foram usados os 30 metros ou mais, conforme indicado pelo Artigo 65.

A aplicação deste novo instrumento de gestão ambiental, permitiu que cerca de 340 edificações fossem desconstituídas, de um total de 8 mil que estavam em processo de regularização fundiária. Cabe lembrar que, apesar da possibilidade de flexibilização na faixa de preservação permanente, a qualidade ambiental não foi negligenciada.

\subsection{Utilização do Governo Eletrônico para regulação ambiental}

O Governo do Distrito Federal tem intensificado suas ações de regulação e fiscalização, com vistas à paralisação do intenso processo de grilagem, bastante corriqueiro na região. Para tanto, faz uso de instrumentos governamentais, considerados de fácil acesso e difusão, os quais fazem parte da política do governo eletrônico.

No site da Terracap (http://www.terracap.df.gov.br), é possível avaliar a situação fundiária de cada condomínio com pendência fundiária, informando, ainda, o status do processo e estágio na etapa de regularização. Ainda, está disponibilizado no site da AGEFIS Agência de Fiscalização do Distrito Federal (http://www.agefis.df.gov.br), um mapa onde são mostradas as áreas sujeitas à infração, caso ocupadas de maneira ilegal e irregular (Figura 1).

Esses instrumentos levam à afirmação das plataformas online do $e$-gov, enquanto instrumentos de acesso à informação, dando ao cidadão conhecimento de como ele deve proceder para regularização fundiária, disponibilizando cartilhas para áreas rurais e para regularização de interesse social, e incluindo as etapas necessárias à regularização. 

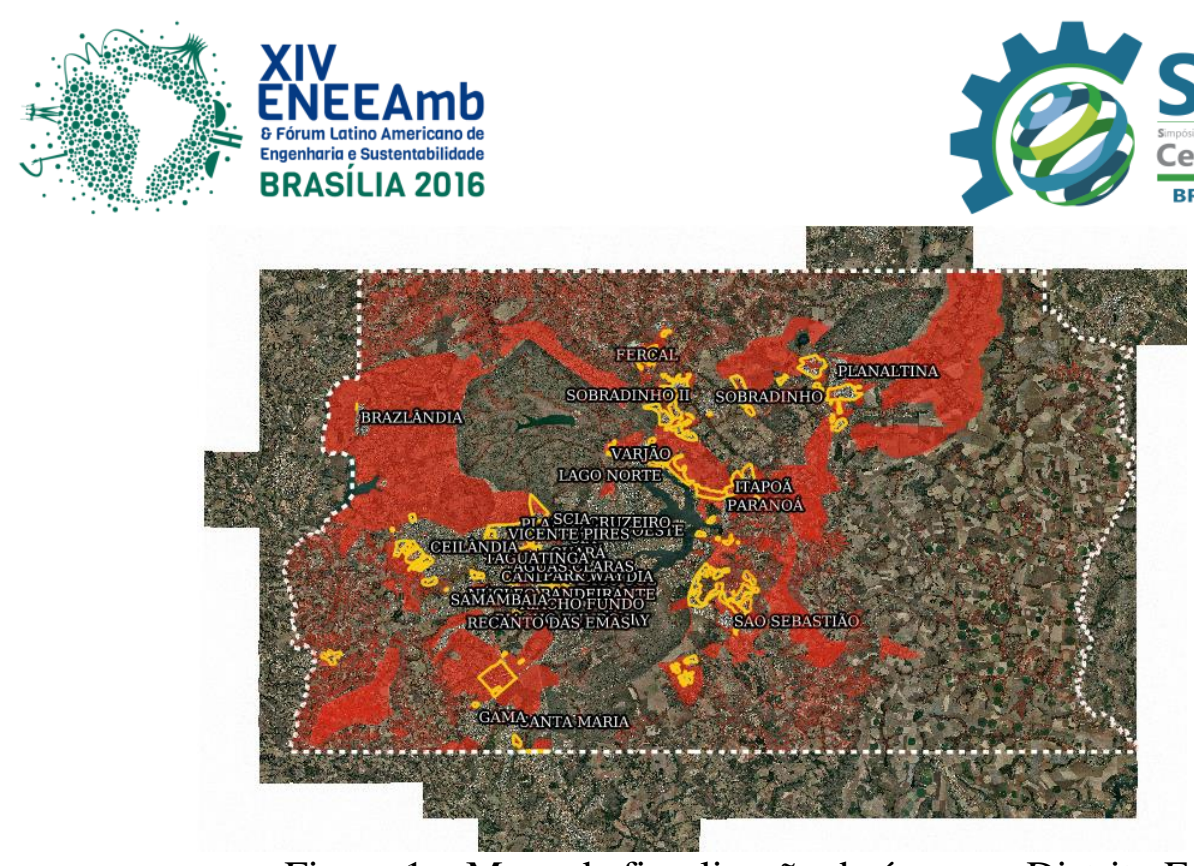

Figura 1 - Mapa da fiscalização de áreas no Distrito Federal.

Fonte: AGEFIS, 2016.

No site da Terracap, o canal de comunicação com o cidadão, o diálogo é feito por meio de acesso à ouvidoria, que pode ser presencialmente, por contato telefônico ou via internet, o que permite registrar reclamações, denuncias, elogios e sugestões, as quais são monitoradas via um protocolo eletrônico emitido. Isso parece demonstrar certa preocupação por parte do órgão em disponibilizar informação ao cidadão de maneira fácil, por várias vias de interação, e que permita o mesmo acompanhar seus registros, e receber retorno da instituição. É importante ressaltar que isso não parecer ser proveniente de uma política de governo eletrônico, mas sobretudo de um canal de ouvidoria regularizado por outros programas e regulamentos governamentais, visto que não há preocupação com a promoção da cidadania, e sim com a regularização pela Lei de acesso à informação.

No que tange ao site da AGEFIS, esta disponibiliza apenas informações básicas sobre os serviços realizados e contatos telefônicos, demonstrando um grau de desenvolvimento do e-gov num nível pouco desejável, diante da magnitude dos problemas ambientais gerados pela ocupação irregular e desordenada.

\section{CONSIDERAÇÕES FINAIS}

A regularização fundiária promove a qualidade ambiental, pois ocorre a implantação de serviços de água tratada, canalização de esgotos, pavimentação das ruas, iluminação pública, coleta de lixo e limpeza pública. Além disso, o registro do imóvel em cartório permite segurança à família e condições efetivas de bem-estar e de integração social. Nestes termos, o Art. 225 da Constituição Federal é atendido, quando as medidas jurídicas, ambientais e sociais que visam à regularização de assentamentos irregulares e à titulação de seus ocupantes, garantem o direito social à moradia, o pleno desenvolvimento das funções sociais da propriedade urbana e o direito ao meio ambiente ecologicamente equilibrado.

Para isso, as Leis Federais $N^{\circ} 12.657 / 2012$ e No $11.977 / 2009$ fornecem os insumos necessários à efetiva regularização de áreas consideradas como de interesse social, garantindo flexibilidade na definição da área de preservação, sem negligenciar a conservação do meio ambiente. Esta análise é de suma importância para a tomada de decisão, uma vez que esses instrumentos foram criados como elemento de promoção social e de sustentabilidade, distanciando-se da ideia de ocupação humana sem preocupação com o meio ambiente.

Ainda, vê-se que, apesar da disponibilidade do acompanhamento das APP ser viabilizado por meio informatizado, esta parece ser o único diferencial que deixa as 

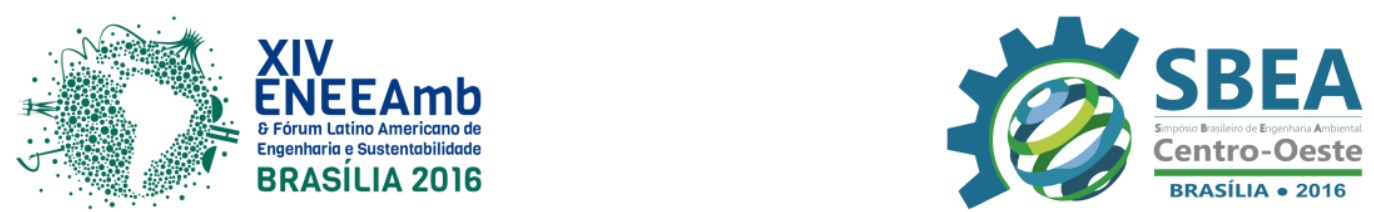

plataformas das principais instituições governamentais envolvidas com a regularização fundiária num nível cujo grau de desenvolvimento do e-gov se manifestaria como regular. As informações são prestadas de maneira clara e os sites possuem acesso fácil, sem demora nos carregamento dos mapas disponíveis, porém pouco interativo em termos de comunicação com o cidadão, e por consequência, pouco promotor de cidadania em termos de conscientização ambiental.

\section{REFERÊNCIAS E CITAÇÕES}

BATISTA, G. V. OLIVEIRA, A.L., SILVA, G., QUEIROZ, C.M. Uso de perfilamento a laser na delimitação de áreas de preservação permanente de curso d'água: estudo de caso na área de regularização fundiária de interesse específico Arniqueira Brasília/Distrito Federal - Brasil. Anais XVI Simpósio Brasileiro de Sensoriamento Remoto - SBSR, Foz do Iguaçu, PR, Brasil, 13 a 18 de abril de 2013, INPE.

BRASIL. Palácio do Planalto. Lei No 11.977, de7 de julho de 2009. Disponível em: http://www.planalto.gov.br/ccivil_03/_ato2007-2010/2009/lei/111977.htm. Acesso em: 28 abril 2016.

Palácio do Planalto. Lei $\mathbf{N}^{\mathbf{0}} \mathbf{1 2 . 6 5 7}$, de 25 de maio de 2012. Disponível em: http://www.planalto.gov.br/ccivil_03/_ato2011-2014/2012/lei/112651.htm. Acesso em: 25 abril 2016.

. Palácio do Planalto. Lei $\mathbf{N}^{\mathbf{0}}$ 12.527, de 18 de novembro de 2011. Disponível em: http://www.planalto.gov.br/ccivil_03/_ato2011-2014/2011/lei/l12527.htm. Acesso em: 28 abril

. Ministério da Ciência e Tecnologia. 2000. Sociedade da informação no Brasil Livro Verde. Takahashi. Brasília.

. Ministério do Meio Ambiente. Resolução do CONAMA no 429/2011. Disponível em: http://www.mma.gov.br/port/conama/legiabre.cfm?codlegi=644. Acesso em: 05 abril

. Ministério do Meio Ambiente. Resolução do CONAMA no 369/2006. Disponível em: http://www.mma.gov.br/port/conama/legiabre.cfm?codlegi=489. Acesso em: 05 abril.

. Instituto Brasileiro de Geografia e Estatística. Censos Demográficos de 2000 e 2010.

GOVERNO DO DISTRITO FEDERAL - CODEPLAN - Disponível em: http://www.codeplan.df.gov.br/images/CODEPLAN/PDF/pesquisa_socioeconomica/pdad/20 04/PDAD_2004.pdf. Acesso em: 25 abril 2016.

Lei 803 de 25 de abril de 2009. Disponível em: $\overline{\mathrm{http}} / / / \mathrm{www} . t \mathrm{tc} . \mathrm{df} . \mathrm{gov} . \mathrm{br} / \mathrm{SINJ} /$ Arquivo.ashx?id_norma_consolidado=60298. Acesso em 26 abril de 2016.

RIBEIRO, C.P.P. et al. Difusão da informação na administração pública. Revista Transformação 23(2): 159-171. Maio/Ago. Campinas, 2011.

JARDIM, J. M. A construção do e -gov no Brasil: configurações político-informacionais. Revista CINFORM. Universidade federal da Bahia. 2005. Disponível em: http://www.cinform.ufba.br/v_anais/artigos/josemariajardim.html. Acesso em Mar 2016. 